\title{
HISTÓRIA AMBIENTAL: ENTRE O PASSADO E O FUTURO
}

Marcelo Lapuente Mahl ${ }^{1}$

Paulo Henrique Martinez ${ }^{2}$

\begin{abstract}
RESUMO
O artigo contém uma visão abrangente do processo de constituição e de institucionalização dos estudos sobre o meio ambiente pelo conhecimento histórico, observado com nitidez a partir da década de 1970, em edição de livros, cursos em universidades e debates historiográficos, em busca de definição deste campo de ensino e de pesquisa. Parte das demandas sociais crescentes, após a II Guerra Mundial, em diferentes países e em escala mundial e privilegia o desenvolvimento da História Ambiental no Brasil. Destaca o caráter interdisciplinar da História Ambiental, percursos historiográficos e possibilidades de novos conhecimentos no século XXI.
\end{abstract}

Palavras-chave: História Ambiental. Interdisciplinaridade. Meio Ambiente

\section{ENVIRONMENTAL HISTORY: BETWEEN PAST AND FUTURE}

\begin{abstract}
The article contains a comprehensive view of the process of constitution and institutionalization of studies on the environment by the historical knowledge, observed clearly from the 1970s, in book publishing, courses in universities and historiographic debates, in search of definition of this field of teaching and research. It starts from the growing social demands, after World War II, in different countries and on a global scale and privileges the development of Environmental History in Brazil. It highlights the interdisciplinary character of Environmental History, historiographic paths and possibilities of new knowledge in the XXI century.
\end{abstract}

Keywords: Environmental History. Interdisciplinarity. Environnmental.

Data de submissão: 15.09 .2021

Data de aprovação: 30.09 .2021

\section{INTRODUÇÃO}

A expressão história ambiental, tradução para a língua portuguesa do original inglês, environmental history, vem sendo cada vez mais adotada para definir uma área de pesquisa, que incorpora, em sua essência, estudos cujo foco principal são as múltiplas (inter)relações entre as sociedades e o meio ambiente. Profundamente marcada pela interdisciplinaridade, a história ambiental trouxe, desde sua origem, nas décadas de 1960 e 1970, a possibilidade de um diálogo amplo e profícuo com diversas áreas do conhecimento, especialmente a geografia, a economia e a ecologia. Entretanto, a essência interdisciplinar dessa temática não a afastou de suas bases teóricas e metodológicas; ela é, na forma como se produz e nas perguntas que formula, essencialmente "histórica".

Os que atuam neste espaço, cujas margens ainda estão em processo de delineamento no Brasil, mas já não se confundem com outros lugares científicos, não perderam de vista os

\footnotetext{
${ }^{1}$ Doutor em História. Docente no Instituto de História e da Faculdade de Educação. Universidade Federal de Uberlândia. E-mail: mlmhistor@hotmail.com.

${ }^{2}$ Doutor em História. Docente na Faculdade de Ciências e Letras de Assis, Departamento de História. Universidade Estadual Paulista. E-mail: martinezph@uol.com.br.
} 
pressupostos fundamentais que balizam o trabalho dos historiadores, especialmente daquele que os distinguem: o estudo das mudanças e permanências das ações e processos humanos ao longo do tempo. A despeito das novas perspectivas temáticas, dos recortes cronológicos singulares e desafiadores e da proximidade com áreas muitas vezes desconhecidas para a maioria dos pesquisadores de outras vertentes, como a zoologia, a botânica e a climatologia, a história ambiental coloca-se, antes de tudo, como "história", ao estudar os processos políticos, econômicos, culturais e sociais a partir de suas conexões com as complexas variáveis do mundo natural.

O primeiro passo para compreender o surgimento da história ambiental como uma área singular de investigação, no âmbito da pesquisa internacional, é a sua intrínseca relação com a emergência do pensamento ambientalista contemporâneo, surgido após a Segunda Guerra Mundial, que ofereceu pela primeira vez, de forma sistêmica e abrangente, a partir de grupos organizados da sociedade civil, órgãos governamentais, ou mesmo de ações individuais, uma visão crítica das ações do homem sobre a natureza. Não resta dúvida que as explosões das bombas atômicas sobre as cidades japonesas de Hiroshima e Nagasaki, e os consequentes danos ligados à contaminação radioativa, que deixaram marcas permanentes nas pessoas e no próprio meio ambiente, podem ser consideradas pontos fundantes dessa nova jornada de consciência, que se desdobrou não somente em conhecimento acadêmico, mas também em movimentos políticos, sociais e culturais, cuja abrangência se estendeu sobre todo o planeta.

Ao mesmo tempo, do ponto de vista institucional, a Organização das Nações Unidas para Alimentação e Agricultura (FAO), passou a avaliar, de forma mais sistemática, o problema da fome como resultado da má gestão dos recursos naturais, se esforçando para compreendê-la e sugerindo modelos de intervenção alternativos, sob a nova perspectiva do assim chamado "desenvolvimento sustentável" (MACCORMICK, 1992). Além disso, no âmbito também das Nações Unidas, se deu um dos mais importantes marcos daquela que podemos chamar de "virada ambientalista": a Conferência das Nações Unidas sobre o Meio Ambiente Humano, de 1972. Organizada na Suécia entre os 5 e 16 de junho, o encontro recebeu mais de uma centena de países, além de várias organizações não-governamentais e cientistas, sendo o primeiro de muitos outros que ocorreriam, a partir de então, sob a chancela da ONU.

Amplamente divulgada na mídia internacional, a chamada Conferência de Estocolmo foi um marco na expansão das questões relativas à proteção ambiental para fora dos espaços políticos ou administrativos dominados por interesses locais ou regionais, estimulando debates transnacionais. O encontro também revelou a importância crescente de uma nova força política e social: a dos "movimentos ambientalistas", em geral, e dos "ecologistas", em particular. A partir desse instante, esses agentes tornaram-se peças fundamentais, e cada vez mais influentes, nos debates relativos ao meio ambiente. Esta movimentação de forças e interesses sociais, impulsionadas pela emergência da temática "ecológica", foram decisivas para que artistas, cientistas, jornalistas, escritores e intelectuais passassem a dedicar cada vez mais atenção à natureza e à sua crescente degradação, demonstrando que o problema já havia sido elevado à condição de tema fundamental da geopolítica internacional no Pós-Guerra.

\section{TRAJETÓRIAS}

Isto não significa que o mundo natural estivesse à margem das atenções nas ciências humanas antes do delineamento epistemológico propriamente dito, especialmente apropriado como objeto de pesquisa pela história ambiental. Entre os autores dos Annales, por exemplo, responsáveis por uma das mais importantes renovações teórico-metodológicas ocorridas na historiografia, a partir do final da década de 1920, a natureza já aparecia de modo relevante. Ela tornou-se mesmo uma força motora no livro de Fernand Braudel, O Mediterrâneo e o mundo mediterrânico na época de Felipe II, publicado em 1949. Já entre os historiadores marxistas, 
especialmente nos trabalhos de Eric J. Hobsbawm, como A Era do Capital e a Era dos Impérios, as condições naturais foram incorporadas às discussões sobre o desenvolvimento das forças produtivas e do modo de produção capitalista.

Foi, principalmente, a partir da década de 1970 que, nos Estados Unidos e na Europa, a chamada história ambiental começou a se constituir enquanto um espaço distinto de conhecimento, com objetos e temas específicos, circunscrevendo seus próprios limites de ação. Um dos primeiros momentos em que a expressão environmental history parece ter sido utilizada foi no ano de 1972, em um artigo publicado pelo historiador Roderick Nash, na Pacific Historical Review. Dois anos antes, Nash já havia ministrado o curso de American Environmental history, na Universidade de Santa Bárbara, na Califórnia, fato que o posiciona como um dos precursores dessa temática nos Estados Unidos (OOSTHOEK, 2005). Outro pesquisador, John Robert Mcneill, também historiador de formação, no artigo Observations on the nature and culture of Environmental History (2003) aponta a importância dos historiadores estadunidenses na demarcação desse campo de investigações.

Dois outros historiadores, Donald Worster e Alfred W. Crosby, tanto pelas pesquisas quanto pelo envolvimento na institucionalização dessa temática, podem ser destacados aqui como precursores dessa abordagem. Até o momento, somente Alfred W. Crosby foi contemplado com edições basileiras, apesar da contemporaneidade do tema. O livro Imperialismo Ecológico - A expansão biológica da Europa: 900-1900, originalmente publicado em 1986, no Brasil, alcançou reedições, já em 1993, 2002 e 2011, por exemplo. Nele, o autor estuda como as condições ambientais locais e a chegada de novas espécies de microorganismos, plantas e animais contribuíram para o avanço do colonialismo europeu, principalmente nas Américas.

Já os livros de Donald Worster, referência fundamental nos estudos de história ambiental, continuam inéditos por aqui. Seu já clássico Dust Bowl: The Southern Plains in the 1930s, examina as tempestades de areia que assolaram os Estados Unidos na década de 1930, resultantes da má utilização do solo agricultável nas plantações do sul do país. Worster e suas propostas para a história ambiental tornaram-se conhecidos dos leitores e pesquisadores brasileiros em dois de seus trabalhos, difundidos em revistas acadêmicas nacionais. Nos artigos, Para fazer História Ambiental (1991) e Transformações da Terra: para uma perspectiva Agroecológica na História (2003) o autor oferece indicações teórico-metodológicas que forneceram pontos de partida e de diretrizes aos trabalhos dos pesquisadores da história ambiental no Brasil.

Destacando o estudo do que denominou constrangimentos ambientais e das formas como os seres humanos interferiram no meio ambiente, como um dos temas mais importantes a ser analisado pelos historiadores ambientais, Worster ofereceu um caminho a ser ao menos compreendido. Ele propõe a divisão das temáticas ambientais em três níveis fundamentais de compreensão: o primeiro nível, formado pelas condições ecológicas propriamente ditas de um determinado objeto. Ao introduzir um ecossistema em seu estudo, por exemplo, historiadores ambientais devem, seguindo esta sugestão de análise, estabeler um estreito diálogo com outras áreas do conhecimento, como a ecologia, a geologia e a botânica, para compreender, de forma apropriada, as diversas e complexas condições naturais que existiram, ou ainda existem, neste espaço. Em um segundo momento, Worster sugere o estudo propriamente dito da interferencia do homem na natureza; dos constrangimentos ambientais causados pela ação humana ao longo do tempo; das transformações do meio natural que foram efetivamente desencadeadas pelas sociedades. Finalmente, em um terceiro nível, pode-se buscar as representações simbólicas construídas por um determinado grupo social sobre o mundo natural, abrindo caminho para o introdução do conceito de cultura nesse tipo de abordagem.

Esta forma de compreender a história ambiental, que é ao mesmo tempo uma proposta metodológica e uma demarcação das fronteiras, acabou por tornar-se uma das mais referidas 
entre os pesquisadores brasileiros. Muitas vezes, dedicando-se somente à análise de um dos níveis propostos por Worster; outras, procurando relacionar os três, certamente um trabalho mais difícil, mas igualmente instigante, a ser executado pelos interessados no assunto.

Há outros trabalhos na historiografia de língua inglesa que podem ser lembrados. Keith Thomas é autor de livro bastante difundido no Brasil, estimulando pesquisas e reflexões. $O$ homem e o mundo natural (1983), remete ao ambiente de debates historiográficos e sociais dos anos setenta. Dedicado ao imaginário e às atitudes diante da natureza, examina o vocabulário, as crenças, provérbios, hábitos e costumes, símbolos e a taxonomia popular de plantas e animais na Inglaterra moderna. Thomas captou o movimento da nova organização intelectual da natureza, apresentando reflexões que permitem melhor compreensão das modernas relações entre homem, sociedade e o mundo natural.

Richard Grove publicou em 1995, Green Imperialism: Colonial Expansion, Tropical Island Edens and the Origens of Environmentalism (1600-1860). Uma reflexão sobre o surgimento dos debates sobre a degradação ambiental nos trópicos. Grove afirma que a observação dos impactos ambientais ocorridos nas colônias, resultantes da exploração desmesurada dos recursos naturais e impulsionada pelas políticas colonialistas européias, foi fundamental para o início da construção do pensamento e dos movimentos ambientalistas tal como os conhecemos. $\mathrm{O}$ autor inseriu as experiências ocorridas no mundo colonial no processo de formação das novas sensibilidades em relação à natureza, incoporando componentes históricos ao processo de formação do pensamento ambiental ocidental moderno, distintos daqueles surgidos no velho continente.

$\mathrm{Na}$ América Latina a dimensão ambiental inicialmente encontrou receptividade entre historiadores da Argentina, Brasil, Chile, Colômbia, Cuba, México e Panamá, a partir da década de 1980, espraiando-se em seguida para outros países. A crise econômica e os efeitos sociais e ambientais das políticas de desenvolvimento impuseram outras abordagens na reflexão sobre o passado e o presente naquelas economias. A indagação encontrou eco tanto em organismos internacionais, como sugere o documento Nuestra propria agenda sobre desarrollo y medio ambiente, quanto em trabalhos de cientistas e acadêmicos em diferentes instituições culturais e universidades latino-americanas. Segundo Guillermo Castro Herrera, da compreensão das "externalidades" do crescimento econômico junto ao meio ambiente passou-se ao questinamento de seus traços característicos, a degradação social e ambiental nos espaços habitados, na cultura e na vida cotidiana das populações urbanas, rurais e indígenas. Abria-se também o caminho para exames dos distintos tempos históricos na relação das sociedades e a natureza nas comunidades e povos nativos da América Latina, assim como os conflitos sociais daí resutantes.

O tripé formado pela expansão de territórios, a produção e extração de matérias-primas e os conhecimentos propulsores destes dois processos, entre 1870 e 1930, foi apontado por Christian Brannstrom e Stefania Gallini como central na transformação de espaços e da cultura dos países latino-americanos. No século XXI, o enlace com o passado parece resssurgir na retomada das monoculturas para a produção de agrocombustíveis, destinados aos mercados industriais do hemisfério norte. O ritmo das trocas de produtos de elevado consumo mundial café, açúcar, soja - ditou ainda o crescimento econômico, os impactos destes na sociedade e na natureza, alcançando ainda as práticas de conhecimento na América Latina.

Em 1991, a publicação de Memoria verde: una historia ecológica de la Argentina, de Antonio Elio Brailovsky e Dina Foguelman, percorreu a história econômica da colonização, da nação independente e das experiências de industrialização naquele país. Os temas do desenvolvimento e das "externalidades" abordados por autores latino-americanos constituiu o ponto de partida para a obra. A pesquisa de Reinaldo Funes Monzote contida em De los bosques a los cañaverales: una historia ambiental de Cuba (1492-1926), sobre o estabelecimento e a trajetória da cana-de-açúcar prolonga a linhagem de estudos históricos sobre esse monocultivo 
canavieiro na ilha e atenta para as novas inquietações sociais e historiográficas. São livros emblemáticos da acolhida que a história ambiental desfrutou na América Latina, ainda que não se tratem dos únicos exemplos possíveis nos últimos vinte anos.

A perseverança na aglutinação de adeptos e novos talentos, debates, a realização de cinco encontros internacionais, uma revista eletrônica, sob o patrocínio institucional da Sociedade Latino-Americana e Caribenha de História Ambiental (SOLCHA), indicam a consolidação deste campo e seus objetos de estudos. Surge uma comunidade de espírito, articulada pela pesquisa e a reflexão, abrindo espaço para a crítica e a interlocução da historiografia na América Latina.

No Brasil, as contribuições de autores e pesquisas realizadas em outros campos do conhecimento histórico pavimentaram alguns dos caminhos que a história ambiental foi trilhando entre nós. A historiografia econômica do século XX vasculhou as atividades dinâmicas da produção agropecuária - cana-de-açúcar, tabaco, café, gado, soja -, do extrativismo - pau-brasil, borracha, erva-mate, madeiras, pesca artesanal, caça às baleias e tartarugas - e a mineração de ouro e diamantes, além da busca incessante pelo petroleo, ferro e carvão. As oportunidades de diálogo e de inspiração nestas análises constavam nas primeiras iniciativas de apresentação e de orientação dos estudos da história ambiental no Brasil (DRUMMOND, 1991). A nossa história ambiental dispõe de aparato crítico no conhecimento da ocupação territorial, das intervenções humanas nos diferentes biomas, da introdução de plantas e animais exóticos à diversidade biológica nativa e da exploração dos recursos naturais naquela mesma dimensão em que, na avaliação de Donald Worster, a historiografia norteamericana, por exemplo, encontrava-se carente quando da disseminação dessa prática historiográfica naquele país (WORSTER, 1991).

Nas duas últimas décadas, tanto a história social quanto a história cultural contribuiram para o alargamento dos interesses da historiografia em direção à natureza e ao meio ambiente. As sensibilidades, as representações, apropriações simbólicas e materiais de elementos do mundo natural - águas, rios, paisagens, florestas, unidades de conservação, espécies da fauna e da flora - a normatização jurídica e política, ações da comunidade científica, movimentos sociais e associativos, vida social e cultura material, atraíram a atenção de pesquisadores e estudiosos na gestação de fecundos diálogos a partir de outras abordagens da própria história, além da antropologia, da economia, da sociologia e geografia ou mesmo da Igreja católica, nos agudos termos da Carta Encíclica Laudato Sí, do Papa Francisco.

Os estudos proporcionados por esta historiografia, de inegável interesse para a história ambiental no Brasil, não tem se furtado ao diálogo em publicações, seminários e debates. Ela também cumpre, inconscientemente até, como em qualquer situação intelectual, um papel de contraponto na definição da identidade analítica e interpretativa dos próprios historiadores das múltiplas interações entre as sociedades e a natureza e das questões meio ambiente.

Quando Warren Dean, historiador norte-americano da economia brasileira, faleceu em Santiago, em 1994, preparava-se para iniciar uma investigação sobre as condições ambientais no Chile. Dean terminara sua volumosa pesquisa sobre a Mata Atlântica, que revestia a costa brasileira quando foi iniciada a colonização européia e que sobreviveu em fragmentos, cercada pelas indústrias, cidades, rodovias, fazendas, usinas e aeroportos. Ele não conheceu a edição do livro, logo, publicado também no Brasil. Ao término da década de 1980, Dean lançara uma história ecológica do extrativismo do látex na Amazônia brasileira, abrindo novas perspectivas para a explicação da economia da borracha na região. A história ambiental no Brasil brotava de uma costela da história econômica de um brasilianista. Os livros de Warren Dean assinalam os estímulos externos, bafejados na historiografia nacional, pelos debates internacionais sobre a questão ambiental, alardeados, desde a década de 1970, em reuniões multilaterais e tratando temas como desenvolvimento econômico, poluição, desmatamento, vida silvestre e educação ambiental. 
Os projetos dos governos militares para converter o Brasil em potência no Atlântico sul, pelos investinentos em infra-estrutura, mineração, indústria, agropecuária e a geração de energia, multiplicaram a rapidez e a intensidade dos efeitos sociais e ambientais dos novos ritmos da atividade econômica. A degradação trazida pelos surtos desenvolvimentistas atravessou o século XX e foi agravada pelos efeitos perenes da crise financeira mundial de 2008, exibindo efeitos duradores nos dias de hoje. A constituição da burocracia estatal dedicada ao meio ambiente, formulações legislativas, propostas pedagógicas e políticas setoriais para unidades de conservação, água e resíduos, por exemplo, repercutiam a mobilização nas universidades e órgãos técnicos, movimentos sociais, Igreja católica e na mídia, sindicatos sensíveis às condições de vida e sáude dos trabalhadores em setores altamnete insalubres, como as indústrias petroquímicas e de cimento, ente outras.

Em pouco tempo os estímulos sociais internos moveriam historiadores e cientistas sociais em indagações sobre o passado ambiental no Brasil. A passagem de Warren Dean pelo curso de História, em Assis, interior de São Paulo, fecundara interesses expressos em artigos e pesquisas de pós-graduandos naquela Faculdade. Publicado em 1987, a dissertação de mestrado A extinção do arco-íris: ecologia e história, de Jozimar Paes de Almeida, sinaliza a ressonância que a história ambiental alcançou naquela década. Em 1988, José Augusto Drummond procurou conhecer as tensões decorrentes dos usos públicos e privados dos ambientes e parques naturais, recorrendo a documentação técnica e governamental, historiografia brasileira e aos presupostos da história ambiental norte-americana. A publicação de Devastação e preservação ambiental no Rio de Janeiro, em 1997, é testemunho da busca deste diálogo em uma conjuntura de tomada de consciência e de debates políticos sobre o meio ambiente no Brasil e da inserção do conhecimento histórico nessas discussões.

$\mathrm{Na}$ década de 1990, estes esforços perduraram, diversficando sujeitos e objetos de estudos, alcançando regiões e temas menos familiares aos livros e análises seminais de Warren Dean. Em 1994, por exemplo, Paulo Bertran examinava a presença humana no planalto central brasileiro, enquanto Victor Leonardi, em 1999, estudava o perímetro do Parque Nacional do Jaú e seu entorno, na porção norte do estado do Amazonas. Nas primeiras décadas deste século os trabalhos publicados, até o momento, revelam a continuidade na variedade de métodos, fontes, objetos e de interesses na historia ambiental. Sem receio de omissões e de simplificação, é possível afirmar que em nossa historiografia dos temas e afinidades ambientais tem predominado a investigação, por um lado, dos conflitos sociais e políticos quanto ao uso e a ocupação dos territórios e seus recursos naturais e, por outro, das interfaces culturais compreendidas em representações, sensibilidades, conhecimentos e concepções (HEYNEMANN, 1995, PRESTES, 2000; ASSUNÇÃO, 2001; PÁDUA, 2002; ARRUDA, ESPÍNDOLA, OLIVEIRA, 2005; JORGE, SOFFIATI, 2006, MARTINEZ, 2007; AYRES, 2008; FADEL, FRANCO E DRUMMOND, MURARI, 2009, BORGES, 2010; SILVA, 2017).

As novas e crescentes pressões em escala mundial sobre os territórios e os recursos naturais em atividades agropecuárias, de infra-estrutura, especulação imobiliária, recursos hídricos e energia, afetam não apenas ambientes e populações ditas tradicionais - indígenas, pequenos proprietários, comunidades rurais, quilombolas e caiçaras - mas igualmente áreas e a vida urbanizada. A característica distintiva do Brasil, neste contexto, é que a sua megadiversidade natural, cultural, étnica e regional responde também pela amplitude de efeitos sociais e ambientais. Sugerem possibilidades e necessidades de estudos e pesquisas que se abrem aos profissionais da história ambiental. A dimensão das tensões e dos confrontos são previsíveis, mas não menos evitáveis. A intensidade e a frequencia destes dependerá da sensiblidade, habilidade e força política dos atores envolvidos e da compreensão crítica desta complexa realidade dos conflitos sociais e ambientais no Brasil.

É provável que as práticas de pesquisa e de ensino escolar e universitário encontrem confluências na dinâmica de ocupação territorial e da exploração econômica na Amazônia, nos 
estudos dos ambientes urbanos, sobre unidades de conservação e políticas públicas para o meio ambiente - gestão participativa, inclusão social, sutentabilidade da vida e do trabalho nas cidades. No âmbito do ensino escolar, universitário e da educação não-formal a história ambiental no Brasil também poderá alcançar êxitos, como revelam sistemáticas preocupações com a formação, o debate e a orientação técnica, teórica e metodológica aos profissionais e estudantes (SOFFIATI, 1990, DUARTE, 2005; MARTINEZ, 2006; MARTINS, 2007, CAROLA, 2009; PÁDUA, 2010).

Nos últimos dois anos, a intensificação da violência social, estatal e privada, e a paralisia, omissão e o desmonte de políticas públicas de meio ambiente, construídas lenta e progressivamente no Brasil, a partir dos anos 1980, têm colocado em evidência mundial a destruição dos biomas, as perdas na biodiversidade e o incremento do uso insustentável dos recursos naturais, particularmente, de solos para agricultura. A expansão das atividades agropecuárias e as insistentes pressões sobre áreas de proteção da natureza, de quilombos, terras indígenas, assentamentos rurais e de usufruto comunitário, talvez respondam pelo teor altamente social que a história ambiental no Brasil irá conhecer e revelar nos próximos anos.

A escala mundial e o ritmo que a degradação ambiental tem conhecido aguça a curiosidade e a criatividade de diferentes sujeitos sociais. As reações ultrapassam os debates das instâncias políticas científicas e dos meios de comunicação. Manifestações públicas povoam as ruas e os espaços abertos - praças, muros, fachadas e viadutos. Elas promovem a reflexão sobre as relações entre as esferas local e global, mobilizam diferentes linguagens artísticas e culturais, do cinema à culinária, do grafite ao funk, com a intenção deliberada de chamar a atenção individual e coletiva para as questões ambientais. Fazem destas princípio e fim de intervenções sociais em que estimulam a opinião pública na tomada de consciência e de decisões no século XXI. A constituição das chamadas humanidades ambientais são um prenúncio de novos caminhos para o ensino e a pesquisa em distintas vertentes do conhecimento da história ambiental, alcançando as artes, a literatura, a música, o teatro, a dança e o cinema, mobilizando novos sujeitos sociais nos debates sobre o meio ambiente, do Papa às crianças, nas praças e escolas. Elas traduzem a integração planetária alcançadas nas últimas décadas.

A incorporação de novos saberes e linguagens ao campo de interesses da história ambiental, ditada pelos comportamentos sociais e a adesão aos valores éticos e estéticos da diversidade biológica e cultural, poderá distinguir em breve a sua prática pedagógica e historiográfica. A renovação de seus dinamismos na pesquisa empírica, na reflexão teórica, na promoção de novas fontes e documentação poderá contribuir ainda na identificação de novos desafios, questões e objetos do conhecimento histórico. O desenvolvimento da história global também poderá representar um reforço da perspectiva de análise em escala planetária, uma demanda constante e crescente nos estudos de história ambiental.

Há riscos também. Na medida em que a informação e os novos conhecimentos, de um lado, tornam-se fundamentais na orientação técnica, científica, pedagógica e cultural de estudantes e de profissionais, por outro, a participação social e o exercício dos direitos e de veres da cidadania toram evidentes a insuficiência da consciência e da informação qualificada. A mobilização e a intervenção nos debates políticos podem conduzir a historiografia do meio ambiente para posturas intelectuais mais prescritivas, alarmistas, fragmentárias, guiadas por interesses e valores particulares, produção, consumo e tecnologias insustentáveis, colocando em risco os direitos humanos, os liames da solidariedade inter e intrageracional, os bem públicos globais, o pensamento e a análise crítica diante de correntes políticas, majoritárias ou não, mas igualmente perturbadoras e que são portadoras de ações e de riscos de comprometimento da objetividade, da compreensão e da verdade cientificamente observadas em escala mundial.

As incessantes inovações técnicas nos meios de informação e de comunicação podem ser também indutoras de um ativismo apressado e imediatista, em geral, reducionista, 
simplificador e irrefletido de causas, avaliações e soluções dos fenômenos e dos processos sociais e culturais abordados, turvando a tomada de decisões em bases participativas e democráticas. No plano historiográfico, a consolidação do regime de historicidade denominado, por François Hartog, como Presentismo tende a contribuir para a ampliação de expectativas sociais, individuais e coletivas, na identificação, proposição e adoção de soluções aos problemas atuais e do futuro, sobretudo, quando vistos em apelos dramáticos e sob perspectivas sombrias e catastróficas. São exemplares, nesta direção, os debates sobre as mudanças climáticas globais, as perdas da biodiversidade, a escassez e contaminação de recursos hídricos, a acelerada redução de estoques pesqueiros, as alternativas para a dependência energética dos combustíveis fósseis, entre outros temas recorrentes.

Por fim, não se pode deixar de apontar, nesta tentativa de localizar a história ambiental em seu breve arco temporal, também dos importantes debates encaminhados a partir de dois conceitos, que tem sido incorporado por cientistas de vários campos do saber, no esforço para compreender e nomear o atual estágio das relações entre as sociedades e o meio ambiente: Antropoceno e Capitaloceno. Estas duas expressões são o foco principal de um grande número de livros e artigos publicados na última década. Mais recentemente, a historiadora Carolyn Merchant lançou The Anthropocene and the Humanities: From Climate Change to a New Age of Sustainability (2020), assim como o filósofo Bruno Latour, que escreveu Diante de Gaia: Oito conferências sobre a natureza no Antropoceno (2020). Entre o filósofo francês e a historiadora norte-americana, em que pese as suas perspectivas teóricas diversas, uma concordância especial se destaca: existe uma urgência pelas reflexões ambientais, postas não somente como um desafio teórico-metodológico para os pesquisadores, mas principalmente como um gesto de responsabilidade para com as futuras gerações, ante os desastres ambientais que se avolumam, apesar da crescente onda de céticos negacionistas, que insistem em fechar os olhos para uma enormidade de fenômenos catastróficos, causados sem dúvida alguma pelas mudanças climáticas, já facilmente observadas.

\section{CONSIDERAÇÕES FINAIS}

Parece existir mesmo um entendimento, compartilhado por centenas de cientistas de todo o mundo, de que a sobrevivência das outras espécies e seus habitat está sendo ameaçada, de forma irreversível, pelo comportamento humano, e que o atual momento talvez seja a última oportunidade para dar início à mudanças estruturais que permitam a recuperação parcial dos recursos naturais, antes que grandes colapsos, de consequências inimagináveis, dificultem a manutenção da vida no planeta, pelo menos do modo como a conhecemos.

Da mesma forma, as atuais sociedades parecem subordinadas cada vez mais às demandas do capital, destituído, até o momento, de ferramentas reguladoras que garantam um equilíbrio entre as forças produtivas e a existência sustentável dos ecossistemas sobreviventes, após mais de dois séculos de espoliação desmesurada da natureza pela sociedades industriais, em suas diferentes etapas de desenvolvimento; processos já muito bem mapeados e conhecidos pelos geógrafos e historiadores ambientais (MCNEILL, 2000; DAVIS, 2007; UEKOETTER, 2010;).

Por fim, partindo dos seus primeiros passos, dados naquele momento inicial à sombra de metodologias e movimentos historiográficos já consolidados, a história ambiental hoje coloca-se como um campo em constante renovação, buscando dialogar com os mais diversos tipos de saberes, oriundos tanto dos consagrados espaços acadêmicos e científicos, quanto do chão de terra batida ocupado por populações tradicionais, especialmente, no caso brasileiro, pelos povos indígenas remanescentes; estes vivamente conectados às demandas, cada vez mais urgentes, por experiências bem sucedidas de convivência com o mundo natural, que porventura possam abrir novas perspectivas para a existência no planeta. 
Entre o passado e o futuro, os historiadores ambientais podem construir uma história radiante - respondendo aos dilemas do tempo presente -, repleta de visões e reflexões ampliadas sobre a experiências e as interações entre os seres vivos no planeta, à luz de suas inserções nas esferas políticas, econômicas, sociais e culturais, tornando-se um campo científico fundamental e, porque não dizer, indispensável, na medida em que "estamos, nessa nova época, diante não apenas de uma natureza que deve ser protegida contra os danos causados pelos homens, mas também de uma natureza capaz de incomodar, de uma vez por todas, nossos saberes e nossas vidas" (STENGERS, 2015).

\section{REFERÊNCIAS}

ALBELDA, José, PARREÑO, José Maria \& MARRERO Henríquez, J. M. (Org.).

Humanidades Ambientales: pensamiento, artes y relatos para el siglo de la gran prueba. Madrid: Catarata, 2018.

ALMEIDA, Jozimar Paes de. A extinção do arco-íris: ecologia e história. Campinas: Papirus, 1988.

ARRUDA, Gilmar (Org.). Natureza, fronteiras e territórios: imagens e narrativas. Londrina: EdUEL, 2005.

ASSUNÇÃO, Paulo de. A terra dos Brasis: a natureza da América. São Paulo: Annablume, 2001.

AYRES, Ana Carolina Moreira. O ciclo da caapora: a RMSP e o Parque Estadual da Cantareira. São Paulo: Annablume, 2008.

BERTRAN, Paulo. História da terra e do homem no planalto central. Ecohistória do Distrito Federal: do indígena ao colonizador. Brasília. Solo, 1994.

BORGES, Ana Carolina da Silva. Nas margens da história: meio ambiente e ruralidade em comunidades "ribeirinhas" do Pantanal Norte (1870-1930). Cuiabá: UFMT/Carlini \& Caniato, 2010.

BRANNSTROM, Christian \& GALLINI, Stefania. "An introduction to Latin American Environmental History", In BRANNSTROM, Christian (Ed.). Territories, commodities and knowledges. London: Institute of Latin American Studies, 2004.

BRAILOVSKY, Antonio Elio \& FOGUELMAN, Dina. Memoria verde: una historia ecológica de la Argentina. 21º edição. Buenos Aires: Debolsillo, 2009.

CAROLA, Carlos Renato. "Meio Ambiente", In PINSKY, Carla Bassanezi (Org.). Novos temas nas aulas de História. São Paulo: Contexto, 2009.

CASTRO, Guillermo. Para una História Ambiental Latinoamericana. La Habana: Editorial Ciencias Sociales, 2004.

CROSBY, Alfred W. Imperialismo ecológico: a expansão biológica da Europa 900-1900. São Paulo: Companhia das letras, 2002. 
DAVIS, Mike. Cidades Mortas. Trad. Alves Calado. Rio de Janeiro: Editora Record, 2007.

DEAN, Warren. A luta pela borracha no Brasil. Trad. E. Brandão. São Paulo: Nobel, 1989.

DEAN, Warren. A ferro e fogo: a história e a devastação da Mata Atlântica brasileira. Trad.

C. K. Moreira. São Paulo: Companhia das Letras, 1996.

DRUMMOND, José Augusto. "A história Ambiental: temas, fontes e linhas de pesquisa".

Estudos Históricos: História e Natureza. Rio de Janeiro: CPDOC/FGV, vol. 4, 1991.

DRUMMOND, José Augusto. Devastação e preservação ambiental no Rio de Janeiro. Niterói: EdUFF, 1997.

DUARTE, Regina Horta. História \& Natureza. Belo Horizonte: Autêntica, 2005.

ESPÍNDOLA, Haruf Salmen. Sertão do rio Doce. Bauru: EDUSC, 2005.

FADEL, Simone. Meio ambiente, saneamento e engenharia no Império e na primeira República. Rio de Janeiro: Garamond, 2009.

FRANCO, José Luis de Andrade \& DRUMMOND, José Augusto. Proteção à natureza e identidade nacional no Brasil, anos 1920-1940. Rio de Janeiro: FIOCRUZ, 2009.

FUNES Monzote, Reinaldo. De los bosques a los cañaverales: una historia ambiental de Cuba (1492-1926). La Habana: Editorial Ciencias Sociales, 2008.

GALLINI, Stefania. "História, ambiente, política: el camino de la historia ambiental en América Latina”. Nómadas 30: 92-102, Bogotá: Universidad Central, abril/2009.

HARTOG, François. Regimes de historicidade: Presentismo e experiências do tempo. Belo Horizonte: Autêntica, 2013.

HEYNEMANN, Claudia. Floresta da Tijuca: natureza e civilização no Rio de Janeiro século XIX. Rio de Janeiro: Secretaria Municipal de Cultura, 1995.

JORGE, Janes. O rio que a cidade perdeu: o Tietê e os moradores de São Paulo, 1890-1940. São Paulo: Alameda/Fapesp, 2006.

LATOUR, Bruno. Diante de Gaia: Oito conferências sobre a natureza no Antropoceno. Trad. Maryalua Meyer. São Paulo: UBU editora, 2020.

LEONARDI, Victor. Os historiadores e os rios. Brasília: UnB/Paralelo 15, 1999.

MARTINEZ, Paulo Henrique. A vida e o mundo: meio ambiente, patrimônio e museus. São Paulo: Humanitas, 2020.

MARTINEZ, Paulo Henrique (Org.). História Ambiental paulista. São Paulo: Senac SP, 2007. 
MARTINEZ, Paulo Henrique. História Ambiental no Brasil: pesquisa e ensino. São Paulo: Cortez, 2006.

MARTINS, Marcos Lobato. História e meio ambiente. São Paulo: Annablume, 2007.

MCCORMICK, John. Rumo ao Paraíso - A história do movimento ambientalista. Rio de Janeiro: Relume-Dumará, 1992.

MCNEILL, J. R. Observations on the Nature and Culture of Environmental History. History and Theory. v. 42, 2003, p. 5-43.

MCNEILL, J. R.. An Environmental History of the Twentieth-Century World. New York: W. W Norton \& Campany, 2000.

MERCHANDT, Carolyn. The Anthropocene and the Humanities: From Climate Change to a New Age of Sustainability. Berkeley: Yale University Press, 2020.

MURARI, Luciana. Natureza e cultura no Brasil (1870-1930). São Paulo: Alameda, 2009.

OLIVEIRA, Rogério Ribeiro de (Org.). As marcas do homem na floresta. Rio de Janeiro: PUC/RJ, 2005.

OOSTHOEK, K. J. W. (2005), What is Environmental History? Disponível em: www.ehresources.org/environmental_history.html. Acesso em: 01 julh. 2011.

PÁDUA, José Augusto. “As bases teóricas da História Ambiental”, Estudos Avançados, 24(68): 81-101, São Paulo: IEA/USP, 2010.

PÁDUA, José Augusto. Um sopro de destruição. Rio de Janeiro: Jorge Zahar, 2002.

PAPA Francisco. Laudato Si': sobre o cuidado da casa comum. São Paulo: Paulinas, 2015.

PRESTES, Maria Elice B.. A investigação da natureza no Brasil colônia. São Paulo: Annablume/Fapesp, 2000.

SILVA, Sandro Dutra. No Oeste, a Terra e o Céu - a expansão da fronteira agrícola no Brasil Central. Rio de Janeiro; Mauad X, 2017,

SOFFIATI, Arthur. O manguezal na história e na cultura do Brasil. Campos: Faculdade de Direito de Campos, 2006.

SOFFIATI, Arthur. "A ausência da natureza nos livros didáticos de história”. Revista Brasileira de História. São Paulo, 9 (19): 43-56, 1989-1990.

STENGERS, Isabelle. No tempo das Catástrofes. Trad. Eloisa Araújo Ribeiro. São Paulo: Cosac Naify, 2015.

THOMAS, Keith. O homem e o mundo natural. Trad. J. R. Martins Filho. São Paulo: Companhia das Letras, 1988. 
UEKOETTER, Frank. The Turning Points of Environmental History. Pittsburgh; University of Pittsburgh Press, 2010.

WORSTER, Donald. "Para fazer História Ambiental". Estudos Históricos. Rio de Janeiro, 4 (8): 198-215, 1991.

WORSTER, Donald. "Transformações da Terra: para uma perspectiva agroecológica na História”. Ambiente e Sociedade. São Paulo, 6(1): 23-44, 2003. 